\title{
Assistência de enfermagem no pré-natal de soropositivas: uma revisão integrativa
}

\author{
Nursing assistance in pre-natal of soropositives: an integrative review \\ Atención de enfermería en pre-navidad de soropositivas: una revisión integradora
}

Recebido: 22/01/2021 | Revisado: 30/01/2021 | Aceito: 09/02/2021 | Publicado: 15/02/2021

Luciana Macêdo dos Santos Rodrigues Portela
ORCID: https://orcid.org/0000-0002-6368-5356
Cristo Faculdade do Piauí, Brasil
E-mail: lucianamacdo89@ gmail.com
Sabrina Beatriz Mendes Nery
ORCID: https://orcid.org/0000-0002-8254-0152
Cristo Faculdade do Piauí, Brasil
E-mail: sabrinaanery2019@gmail.com
George Marcos Dias Bezerra
ORCID: https://orcid.org/0000-0002-4720-9077
Cristo Faculdade do Piauí, Brasil
E-mail: enfermeirogeorgemarcos@gmail.com
Joyciane Soares Araújo Mendes
ORCID: https://orcid.org/0000-0003-4788-8281
Cristo Faculdade do Piauí, Brasil
E-mail: joycearaujo1326@ gmail.comr
Guilherme Antônio Lopes de Oliveira
ORCID: https://orcid.org/0000-0003-3820-0502
Cristo Faculdade do Piauí, Brasil
E-mail: guilhermelopes@ live.com
Almiro Mendes da Costa Neto

\section{Resumo}

Objetivo: identificar as condutas do enfermeiro ao atender uma gestante soropositiva Metodologia: trata-se de uma revisão integrativa de abordagem qualitativa, com as pesquisas realizadas na base de dados online Portal Regional da Biblioteca Virtual em Saúde (BVS) e em seus sites afiliados. Incluíram-se publicações divulgadas entre 2011 e 2019 , com texto completo, artigos, monografias e teses nos idiomas português e inglês, disponíveis de forma gratuita, que atendessem até três descritores utilizados. Foram excluídos trabalhos com data inferior a 2011, também àquelas que apresentavam apenas resumos e citações com idiomas diferentes dos citados anteriormente. $\mathrm{O}$ estudo foi composto pela análise de 10 publicações. Resultados: É indispensável à assistência e a orientação do enfermeiro sobre prevenir riscos e problemas, não necessitando limitar ações clínico-obstétricas, e acrescentar ações de educação em saúde como prática habitual da assistência integral. Assim as habilidades do enfermeiro ao longo do pré-natal de soropositivas sobressaem métodos educativos para a prevenção do HIV diante do binômio mãe/filho. Conclusão: percebeu-se que a infecção pelo HIV nos últimos anos vem crescendo, e o enfermeiro possui um papel importantíssimo na Atenção Primária de Saúde (APS) pois vem contribuindo bastante para a diminuição da transmissão desse vírus em gestantes soropositivas.

Palavras-chave: Atenção primária à saúde; Cuidado pré-natal; Enfermeiros; AIDS.

\begin{abstract}
Objective: to identify the nurse's conduct when attending a pregnant woman with HIV Methodology: this is an integrative review of a qualitative approach, with the researches carried out in the online database of the Regional Portal of the Virtual Health Library (VHL) and in its affiliated sites. Publications published between 2011 and 2019 were included, with full text, articles, monographs and theses in Portuguese and English, available free of charge, covering up to three used descriptors. Works with a date lower than 2011 were excluded, also those that presented only abstracts and citations with languages other than those previously mentioned. The study consisted of an analysis of 10 publications. Results: It is essential to the assistance and guidance of nurses on preventing risks and problems, not needing to limit clinical-obstetric actions, and adding health education actions as a usual practice of comprehensive care. Thus, nurses' skills throughout prenatal care for HIV-positive women stand out in educational methods for HIV prevention in the face of the mother / child binomial. Conclusion: it was noticed that HIV infection in recent years has been growing, and nurses have a very important role in Primary Health Care (PHC) because it has contributed a lot to reduce the transmission of this virus in HIV-positive pregnant women.
\end{abstract}


Keywords: Primary health care; Prenatal care; Nurses; AIDS.

\section{Resumen}

Objetivo: identificar la conducta de las enfermeras al atender a una mujer embarazada con VIH. Metodología: esta es una revisión integradora de un enfoque cualitativo, con las investigaciones realizadas en la base de datos en línea del Portal Regional de la Biblioteca Virtual en Salud (BVS) y en sus sitios afiliados. Se incluyeron publicaciones publicadas entre 2011 y 2019, con texto completo, artículos, monografías y tesis en portugués e inglés, disponibles de forma gratuita, que cubren hasta tres descriptores utilizados. Se excluyeron los trabajos con una fecha inferior a 2011, también aquellos que presentaban solo resúmenes y citas con idiomas distintos a los mencionados anteriormente. El estudio consistió en un análisis de 10 publicaciones. Resultados: es esencial proporcionar asistencia y orientación a las enfermeras para prevenir riesgos y problemas, no es necesario limitar las acciones clínico-obstétricas y agregar acciones de educación para la salud como una práctica habitual de atención integral. Por lo tanto, las habilidades de las enfermeras durante la atención prenatal para mujeres VIH positivas se destacan en los métodos educativos para la prevención del VIH frente al binomio madre / hijo. Conclusión: se notó que la infección por VIH en los últimos años ha estado creciendo y las enfermeras tienen un papel muy importante en la Atención Primaria de Salud (APS) porque ha contribuido mucho a reducir la transmisión de este virus en mujeres embarazadas VIH positivas, evitando así la TV.

Palabras clave: Atención primaria de salud; Cuidado prenatal; Enfermeras; SIDA.

\section{Introdução}

O Vírus da Imunodeficiência Humana (HIV) afeta o organismo e destrói as células de defesa do corpo. Dentre as células com maior comprometimento, os linfócitos T CD4+ são as células mais atingidas. Essas células coordenam a função de defesa imunológica contra vírus, bactérias e fungos através da proteção e produção de citocinas e interleucinas. Hoje essa patologia é dos maiores enigmas enfrentados pela humanidade representando um desafio para a medicina e a ciência na busca de uma terapêutica (Beck et al., 2018).

O HIV já contaminou entre 50 e 60 milhões de indivíduos e causou óbito de mais de 25 milhões de adultos e crianças. E cerca de 35 milhões de indivíduos encontram-se infectados pelo HIV e pela Síndrome da Imunodeficiência Adquirida (AIDS). A AIDS deixou aproximadamente 14 milhões de órfãos. No momento atual, não existe vacina ou cura definitiva para a AIDS, mas perduram medicamentos antirretrovirais satisfatoriamente desenvolvidos, que são eficazes e capazes de controlar a infecção. Existem três vias fundamentais pelas quais o HIV pode ser disseminado: o contato sexual, a transmissão de um receptor com sangue contaminado e a transmissão de mãe para filhos, que pode acontecer na vida intrauterina, durante o parto ou através da amamentação (Araújo et al., 2018).

A assistência às gestantes soropositivas é de suma importância e o cuidado deve ser humanizado, individualizado e através de uma equipe multiprofissional por se tratar de uma gestação de alto risco, alcançando o propósito de certificar o encorajamento para enfrentar as principais dificuldades vividas por elas. Desta maneira, a assistência desse público deve seguir cuidadosamente e evitando julgamentos, discriminação e preconceito. Neste momento, os profissionais devem ter muita sensibilidade para abarcar o choque vivenciado por essas mulheres, em ser gestante e estar infectada pelo vírus do HIV (Lima et al., 2018).

Evidencia-se que o trabalho da Equipe de Saúde da Família (eSF) dentro da Estratégia Saúde da Família (ESF) é importante, pois o enfermeiro pretende ser o mais próximo da população quando se leva em consideração a sua forma de trabalho. Para Beck et al. (2018) a enfermagem vem conseguindo aumentar seu espaço na saúde, cada vez mais encarregado e protagonista no cuidado aos indivíduos. Pois, apesar de estar relacionada com outras áreas da saúde, a enfermagem mostra sua importância em relação ao cuidado de forma integralizada dos serviços de saúde.

O pré-natal realizado desde o início da gestação permite antecipar a detecção de riscos e prevenir complicações futuras. Pois, dentre as políticas de enfrentamento, enfatiza-se que o Ministério da Saúde (MS) preconiza o reconhecimento precoce da infecção pelo HIV na gestação para adotar ações profiláticas que, de fato minimizem a transmissão materno-infantil do HIV. Na atualidade, a AIDS é um problema de saúde pública a nível mundial, com aumento de crianças contaminadas pelo 
HIV, no qual o contágio pode ocorrer no decorrer da gestação, com um aumento no segundo trimestre, no momento do parto e no período da amamentação (Silva \& Silva, 2018). Através do aprofundamento e da importância que dá ao tema, consubstanciou-se as reflexões sobre os dados que embasam o presente estudo, dessa forma, essa pesquisa teve como objetivo geral identificar as condutas do enfermeiro ao atender uma gestante soropositiva.

\subsection{Atribuições do enfermeiro na Estratégia Saúde da Família (ESF)}

O enfermeiro da ESF exerce importante função, retomando a relação entre enfermeiro e família, na tentativa de colaborar para o aprimoramento da condição de saúde e de vida do indivíduo no ambiente familiar. O profissional deve estar capacitado para planejar, desenvolver, organizar e avaliar condutas que respondam a carência da comunidade, além de dar continuidade ao cuidado e orientar sobre as ações que devem ser realizadas de acordo com suas necessidades (Coelho, 2018).

Com isso, a ESF é vista pela enfermagem segundo Matumoto et al. (2011) como um símbolo de oportunidade para reorganizar sua assistência da melhor maneira possível, indo de encontro às necessidades expostas pela população que necessita de seus serviços ao invés de pensar apenas em simplificar o serviço médico. Os enfermeiros na estratégia atuam sempre buscando solucionar os problemas e melhorar as condições de seus clientes que o procuram, esse deve ser um dos principais objetivos de seu trabalho dentro da unidade, realizarem suas ações para o benefício populacional.

Em 1994 o Programa Saúde da Família (PSF) aos poucos foi se tornando uma importante estratégia para o engrandecimento do acesso de primeiro contato e de mudança do modelo assistencial. Em 2006 foi anunciada pela Política Nacional de Atenção Básica (PNAB) como ESF. Esta é aprovada pela portaria n 2.436, de 21 de setembro de 2017. A PNAB define as atribuições do enfermeiro dentro da Atenção Básica de Saúde (ABS) no país, esse profissional é responsável por prestar assistência aos usuários cobertos pela eSF de forma longitudinal, executar procedimentos necessários, realizar a supervisão da recepção dos clientes, fazer uma avaliação sobre as condições saudáveis encontradas na sua área junto com a equipe, utilizar de encaminhamentos para outras modalidades de serviço quando achar necessário, coordenar as ações executadas por técnicos de enfermagem, colocar em prática circunstâncias que melhorem a qualidade do seu serviço na unidade (Brasil, 2017).

Segundo Caus et al. (2012), o enfermeiro está se destacando em vários segmentos, como: assistência, pesquisa, consultoria, ensino e avançando no processo que existe entre o cuidado e a educação em saúde. Entre uma das características do enfermeiro, encontra-se a imagem de um profissional cuidador, que demonstra esse cuidado quando educa o paciente por meio de orientações, tornando a educação em saúde uma maneira de realizar esse cuidado e fazendo do cuidado uma forma de realizar a educação em saúde.

\subsection{Assistência de enfermagem a Gestantes Soropositivas na ESF}

O desempenho do enfermeiro, na unidade de saúde da família, frente às gestantes soropositivas deve ser fundamentado na interação e na relação de confiança. O papel do enfermeiro sempre é o da orientação, com foco na escuta, acatando sua individualidade sendo estas biológicas, psicossociais e culturais. Em sua assistência, o enfermeiro deve focar em atitudes éticas e de sensibilidade, consentindo a expressão de sentimentos por parte dos que precisam do enfermeiro, e evitando moralismo relacionado a conhecimentos técnicos e científicos (Goulart et al., 2018).

A antiga resolução do Conselho Federal de Enfermagem (COFEN) no 0478 de 2015 dizia que apenas enfermeiro obstetra e obstetriz podiam atuar e responsabilizar-se nos Centros de Parto Normal e/ou de Casas de Parto. Em 2016 o COFEN lança uma nova resolução de $n^{\circ} 524$ que insere nessa lista o enfermeiro generalista, atuando na assistência às gestantes, parturientes, puérperas e recém-nascidos; esse vínculo designa critérios para registros de títulos de enfermeiro obstetra e obstetriz no contexto do sistema COFEN (COFEN, 2016). 
O enfermeiro dispõe de um papel considerável diante de um diagnóstico sorológico de HIV positivo durante a gestação, destacando-se nos processos de acolhimento, vínculo e educação em saúde. Ressalta-se que é necessária a confirmação do diagnóstico da paciente ainda na gestação, para que assim o tratamento ou a profilaxia seja iniciado. As recomendações do MS informam que todas as gestantes devem ser encorajadas a realizar o teste anti-HIV na primeira consulta de pré-natal e se possível no início do terceiro trimestre de gestação. $\mathrm{O}$ ato de cuidar do enfermeiro baseia-se na integralidade e compreensão das necessidades do outro (Araújo, Monte \& Haber, 2018).

O pré-natal pode ser acompanhado integralmente pelo enfermeiro, pois apresenta fundamentos teórico-científicos e amparo legal para proporcionar uma assistência qualificada na rede de Atenção Básica de Saúde (ABS). Destacamos a importância da realização do pré-natal e do enfermeiro, para o bem-estar da gestante e do feto, visto que a condição da assistência ofertada durante as consultas de pré-natal realizadas pelo enfermeiro pode diminuir os números de mortalidade materna e infantil, assim como as doenças relacionadas à gestação e a Transmissão Vertical (TV) de possíveis agravos no decorrer da gestação (Cunha et al., 2017).

\subsection{Gestação e a importância do pré-natal}

A gestação ocasiona modificações orgânicas e psicológicas exclusivas do processo fisiológico que define este período. Tais modificações devem ser assistidas por profissionais preparados para identificar precocemente fatores de risco que possam indicar alterações e comprometer o bem-estar materno-fetal. Dessa forma, permite-se adotar condutas apropriadas, para que a gestação resulte com a chegada de um recém-nascido saudável e uma mãe livre de complicações (Balsells, 2018).

O Programa de Assistência Integral à Saúde da Mulher (PAISM), a Política Nacional de Atenção Integral à Saúde da Mulher (PNAISM) e a Rede Cegonha (RC) foram preparados no intuito de construir uma rede de assistência humanizada para mulheres, que prevê ações desde o período pré-natal, parto e atenção integral materno e infantil através de um sistema logístico (Bispo, 2018).

Em 2000, o MS através da Portaria/GM n 569, de 01 de junho 2000 o Programa de Humanização no Pré-natal e Nascimento (PHPN). Sua principal estratégia seria promover melhor acesso ao acompanhamento pré-natal, dar assistência no parto e puerpério às gestantes e ao recém-nascido, consistindo no direito à humanização compreendendo dois aspectos fundamentais. No primeiro, é responsabilidade das unidades de saúde acolher com dignidade a mulher, seus familiares e o recém-nascido. O segundo compete à adesão de medidas e procedimentos notoriamente vantajosos para o acompanhamento do parto e do nascimento, prevenindo práticas intervencionistas desnecessárias (Brasil, 2000).

A atenção pré-natal visa colaborar para a diminuição da morbimortalidade materna e infantil. Uma assistência de qualidade deve colaborar com ações resolutivas e acolhedoras, bem como sistematizar e simplificar o acesso adequado à atenção básica e a outros níveis de atenção da rede de serviços de saúde, procurando garantir assistência apropriada com relação à gestação e ao parto (Silva \& Santana, 2013).

A sistematização à saúde na gestação de alto risco estabelece normas para a implantação e aptidão dos serviços de referência. O pré-natal de alto risco será executado de acordo com a individualidade de cada usuária, com inclusão à atenção básica, a qual incumbe a coordenação da assistência, com a segurança de uma atenção à saúde progressiva, continuada e de fácil acesso para todas as mulheres (Coelho, 2018).

Em relação ao Pré-Natal de Alto Risco (PNAR), é recomendada a avaliação dos riscos clínicos e obstétricos a cada consulta, além da segurança de usufruir de um excelente atendimento e de acesso ao setor de referência ambulatorial e hospitalar. O manual técnico do MS para a gestação de alto risco, por sua vez, norteia a equipe de saúde no diagnóstico e no tratamento das intercorrências e padroniza as condutas, colaborando para uma assistência coerente e eficiente. Assim, o 
enfermeiro pode trabalhar em equipe e com atividades próprias, alcançando seus objetivos estratégicos com eficiência (Lima et al., 2018).

\section{Metodologia}

O presente trabalho trata-se de uma revisão integrativa com abordagem qualitativa. Nesta metodologia, deu-se início com a escolha de uma questão que norteou a pesquisa. Sendo assim, esta primeira etapa teve grande relevância no desenvolvimento de uma revisão integrativa bem estruturada, pois o tema central é delimitado claramente e de forma específica, objetivando um estudo focado e completo com conclusões de fácil compreensão. Portanto, essa pesquisa teve como questão norteadora: Quais as condutas do enfermeiro na assistência do pré-natal de soropositivas?

As pesquisas foram feitas utilizando as bases de dados online Portal Regional da Biblioteca Virtual em Saúde (BVS) e seus sites afiliados. A procura sucedeu fazendo uso de palavras que representam o assunto tratado no corpo do trabalho, isto é, os chamados descritores com existência constatada através do vocabulário estruturado (DeCS) (Descritores em Ciência da Saúde), sendo eles "Atenção Primária a Saúde”," Enfermagem", "Cuidado Pré-natal”, “AIDS”.

Preferiu-se pela busca de publicações divulgadas entre 2011 e 2019 com texto completo, artigos, monografias nos idiomas português e inglês, disponíveis de forma gratuita, que atendessem até três descritores utilizados. Foram excluídos trabalhos com data inferior a 2011 (exceto em casos da descrição de leis, portarias e manuais), também aquelas que apresentavam apenas resumos e citações com idiomas diferentes dos citados anteriormente.

Após realizar uma busca na base de dados BVS, utilizando as estratégias de busca citadas anteriormente, chegou-se a um total de 20 achados. Realizada então a análise desses artigos, por meio da leitura dos títulos e resumos, observando sua relação ao tema proposto e atentando-se para os estudos em duplicidade, restaram apenas 10 artigos inclusos neste estudo.

Os dados foram organizados em um quadro síntese para posterior discussão, sendo que as informações contidas dividiram da seguinte forma: ordem, título, autores, ano de publicação, ode, objetivos e principais achados.

O estudo dispensa a apreciação de Comitê de Ética em Pesquisa pois é fundamentado em dados de acesso livre.

\section{Resultados e Discussão}

A princípio foi produzido um quadro para exibir as pesquisas abrangendo informações como ordem, título, autores e ano de publicação dos estudos. Após a consulta nas bases de dados por meio dos descritores e após a utilização dos critérios de inclusão e exclusão determinados, foram selecionados 10 artigos presentes no Quadro 1 para análise da revisão integrativa. 
Quadro 1 - Artigos selecionados durante a pesquisa por evidências. Os artigos foram apresentados de acordo com a ordem, título, autores e ano de publicação.

\begin{tabular}{|c|c|c|c|}
\hline ORDEM & TÍTULO & AUTOR(ES) & $\begin{array}{c}\text { ANO DE } \\
\text { PUBLICAÇÃO }\end{array}$ \\
\hline 1. & $\begin{array}{lccc}\text { Transmissão } & \text { Vertical do } & \text { HIV: } \\
\text { Dificuldade na adesão ao Pré-Natal }\end{array}$ & Santos et al. & 2017 \\
\hline 2. & $\begin{array}{l}\text { Assistência de enfermagem à mãe e } \\
\text { bbbê portadores de HIV/AIDS. }\end{array}$ & Ribeiro et al. & 2017 \\
\hline 3. & $\begin{array}{l}\text { Percepção do enfermeiro da atenção } \\
\text { básica acerca do atendimento à } \\
\text { gestante soropositiva }\end{array}$ & Goulart et al. & 2018 \\
\hline 4. & $\begin{array}{l}\text { Vertical transmission of hiv: } \\
\text { reflections about health promotion and } \\
\text { nursing care }\end{array}$ & Lima et al. & 2017 \\
\hline 5. & $\begin{array}{l}\text { O trabalho do enfermeiro no pré-natal } \\
\text { de alto risco sob a ótica das } \\
\text { necessidades humanas básicas }\end{array}$ & Errico et al. & 2017 \\
\hline 6. & $\begin{array}{l}\text { Cuidado de enfermagem diante da } \\
\text { prevenção da transmissão vertical do } \\
\text { HIV. }\end{array}$ & Costa, Silva \& Medeiros & 2015 \\
\hline 7. & $\begin{array}{l}\text { Educational technologies and practices } \\
\text { for prevention of vertical HIV } \\
\text { transmission. }\end{array}$ & Lima et al. & 2018 \\
\hline 8. & $\begin{array}{l}\text { A enfermagem e a prevenção da } \\
\text { transmissão vertical do HIV: uma } \\
\text { revisão integrativa }\end{array}$ & Silva \& Silva & 2018 \\
\hline 9. & $\begin{array}{l}\text { Práticas alternativas de vínculo ao } \\
\text { binômio mãe/filho para mães } \\
\text { soropositivas para HIV }\end{array}$ & Carvalho \& Campos & 2018 \\
\hline 10. & 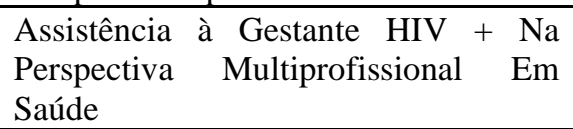 & Barrêto \& Souza & 2019 \\
\hline
\end{tabular}

Fonte: Autores (2019).

Identificou-se que dos 10 artigos escolhidos, 01 (10\%) corresponde ao ano de 2015, 04 (40\%) datam do ano de 2017, 04 de 2018 (40\%). Foi encontrada apenas 01 publicação (10\%) referente ao ano de 2019.

Com os dados obtidos por meio da análise dos artigos, observou-se que de 2015 a 2019, o maior número de publicações concentrou-se no ano de 2017 e 2018. O oposto foi encontrado nos anos anteriores a 2015 houve poucas publicações a respeito do tema discutido.

O Quadro 2 traz informações sobre as publicações utilizadas, como estudo, objetivos e principais achados. 
Quadro 2 - Estudo, objetivo e principais achados de estudos para análise da revisão integrativa.

\begin{tabular}{|c|c|c|}
\hline ESTUDO & OBJETIVO & PRINCIPAIS ACHADOS \\
\hline 1. & $\begin{array}{l}\text { - Verificar nas produções científicas as } \\
\text { dificuldades dos enfermeiros com relação } \\
\text { a mulheres HIV positivas em aderir o pré- } \\
\text { natal. }\end{array}$ & $\begin{array}{l}\text { Os fatores incluídos à dificuldade na } \\
\text { adesão ao pré-natal são múltiplos e estão } \\
\text { coligados a diversas causas; } \\
\checkmark \quad \text { Outras maneiras que atrapalham a } \\
\text { concretização do pré-natal: acesso aos } \\
\text { serviços de saúde, descontinuidade na } \\
\text { realização das consultas e não adesão ao } \\
\text { tratamento. }\end{array}$ \\
\hline 2. & $\begin{array}{l}\text { - Identificar ações de enfermagem a ser } \\
\text { prestada a gestante portadora de } \\
\text { HIV/AIDS no pré-natal. }\end{array}$ & $\begin{array}{l}\text { O acompanhamento e orientação sobre } \\
\text { precaver riscos e dificuldades, não } \\
\text { devendo se limitar as ações clínico- } \\
\text { obstétricas, e incluir ações de educação } \\
\text { em saúde na rotina da assistência } \\
\text { integral; } \\
\checkmark \text { Aconselhamento em DSTs, diagnóstico } \\
\text { da infecção pelo HIV, abordagem } \\
\text { sindrômica. }\end{array}$ \\
\hline 3. & $\begin{array}{l}\text { - Identificar a atuação do enfermeiro na } \\
\text { atenção básica diante do atendimento de } \\
\text { gestantes soropositivas. }\end{array}$ & $\begin{array}{l}\text { As ações do enfermeiro, na unidade de } \\
\text { saúde da família, diante às gestantes } \\
\text { HIV+ deve ser pautada na interação e na } \\
\text { relação de confiança. A função do } \\
\text { enfermeiro sempre é o da orientação, } \\
\text { com foco na escuta sobre as } \\
\text { preocupações e dúvidas; } \\
\text { Em seu atendimento, o enfermeiro deve } \\
\text { pautar-se em atitudes éticas e de } \\
\text { sensibilidade, permitindo a expressão de } \\
\text { sentimentos, evitar atitudes moralistas e } \\
\text { de juízos de valores relacionados a } \\
\text { conhecimentos técnicos e científicos, o } \\
\text { que aponta para um grande desafio para } \\
\text { a efetivação do aconselhamento. }\end{array}$ \\
\hline 4. & $\begin{array}{l}\text { - Fornecer subsídios para que melhorem a } \\
\text { qualidade da assistência prestada às mães } \\
\text { e crianças expostas ao HIV. }\end{array}$ & $\begin{array}{l}\text { O enfermeiro, juntamente com uma } \\
\text { equipe multiprofissional, realiza } \\
\text { atividades no intuito de prevenir a TV do } \\
\text { HIV; } \\
\checkmark \text { O enfermeiro atua na condição de } \\
\text { educador, podendo atuar na linha do } \\
\text { cuidado, desde o período } \\
\text { préconcepcional, pré-natal, parto até o } \\
\text { puerpério. }\end{array}$ \\
\hline 5. & $\begin{array}{l}\text { - Analisar o trabalho do enfermeiro no } \\
\text { pré-natal de alto risco na atenção } \\
\text { secundária, considerando os problemas de } \\
\text { enfermagem e as necessidades humanas } \\
\text { básicas das gestantes }\end{array}$ & $\begin{array}{l}\checkmark \text { O MS preconiza o atendimento da } \\
\text { gestante no PNAR por equipe } \\
\text { multidisciplinar, que inclui o profissional } \\
\text { enfermeiro; } \\
\checkmark \text { Dentre as ações do enfermeiro em uma } \\
\text { equipe multidisciplinar esta a consulta de } \\
\text { enfermagem, elaboração e o } \\
\text { planejamento das ações de cuidado } \\
\text { necessários baseados em evidências } \\
\text { científicas, e atuação limitada em } \\
\text { espaços onde há o predomínio das } \\
\text { tecnologias dura e leve-dura. }\end{array}$ \\
\hline 6. & $\begin{array}{l}\text { - Analisar os aspectos do cuidado de } \\
\text { enfermagem diante da prevenção da } \\
\text { transmissão vertical do HIV }\end{array}$ & $\begin{array}{l}\text { Apesar de estar previsto que a atenção à } \\
\text { gestante no PNAR deva ser desenvolvida } \\
\text { por uma equipe multiprofissional, } \\
\text { identifica-se que a atuação do enfermeiro }\end{array}$ \\
\hline
\end{tabular}




\begin{tabular}{|c|c|c|}
\hline & & $\begin{array}{l}\text { na atenção secundária não é consistente } \\
\text { com o espectro de suas competências } \\
\text { técnicas; } \\
\checkmark \text { A atuação desse profissional diante da } \\
\text { prevenção da transmissão vertical é de } \\
\text { suma importância e envolta de muitas } \\
\text { possibilidades; porém, ainda é decorrida } \\
\text { por algumas dificuldades e desafios. }\end{array}$ \\
\hline 7. & $\begin{array}{l}\text { - Avaliar as evidências disponíveis sobre } \\
\text { as tecnologias e práticas educativas para } \\
\text { prevenção da transmissão vertical do HIV }\end{array}$ & $\begin{array}{l}\text { Os enfermeiros, como profissionais } \\
\text { vocacionados para a educação em saúde, } \\
\text { vêm utilizando tecnologias para mediar o } \\
\text { cuidado prestado ao indivíduo assistido. } \\
\text { As tecnologia são descritas como: leve, } \\
\text { dura e leves-dura. } \\
\checkmark \text { As tecnologias leves fazem parte do } \\
\text { cotidiano das ações de enfermagem no } \\
\text { Pré-natal de soropositivas. }\end{array}$ \\
\hline 8. & $\begin{array}{l}\text { - Enfatizar a contribuição da assistência } \\
\text { de enfermagem na redução dos riscos de } \\
\text { transmissão vertical pelo Vírus da } \\
\text { Imunodeficiência Humana (HIV) }\end{array}$ & $\begin{array}{l}\checkmark \text { enfermeiro, como integrante da equipe } \\
\text { de saúde, assume as ações e } \\
\text { responsabilidade voltadas para o cuidado } \\
\text { de enfermagem; } \\
\checkmark \text { O enfermeiro tem uma importância } \\
\text { significativa dentro desse contexto, pois } \\
\text { é responsável pela identificação precoce } \\
\text { dessa gestante HIV+. }\end{array}$ \\
\hline 9. & $\begin{array}{l}\text { - Identificar as principais estratégias } \\
\text { complementares que o profissional } \\
\text { enfermeiro possa orientar para que sejam } \\
\text { utilizadas com a finalidade de promover o } \\
\text { aumento do vínculo entre o binômio mãe } \\
\text { e filho em mães soropositivas para HIV. }\end{array}$ & $\begin{array}{l}\text { É responsabilidade do enfermeiro o } \\
\text { acompanhamento do binômio e } \\
\text { identificar possíveis dificuldades } \\
\text { relatadas pela mãe para interagir com seu } \\
\text { filho verticalmente exposto; } \\
\checkmark \text { O enfermeiro pode fundar ações que } \\
\text { cooperem para comunicação da ligação } \\
\text { afetiva da mãe com seu bebê. }\end{array}$ \\
\hline 10. & $\begin{array}{l}\text { - Incluir a atuação do enfermeiro na } \\
\text { assistência às gestantes HIV+ }\end{array}$ & $\begin{array}{l}\checkmark \text { O enfermeiro está responsável pelo } \\
\text { primeiro contato com as gestantes HIV+ } \\
\text { e a partir deste acolhimento, inicia-se o } \\
\text { fluxo da assistência multiprofissional; } \\
\checkmark \text { A OMS afirmou que } 80 \% \text { das questões } \\
\text { de saúde deveriam ser resolvidas na } \\
\text { Atenção Primária Saúde (APS). }\end{array}$ \\
\hline
\end{tabular}

Fonte: Autores (2019).

\subsection{As condutas do Enfermeiro no atendimento a gestante soropositiva}

Considerando o objetivo principal da pesquisa que é o de identificar as condutas de enfermagem no pré-natal de soropositivas pode perceber que existe uma série de condutas a serem tomadas, assim como as normas e medidas preventivas para o controle da TV estão definitivamente protocoladas. Neste contexto, foi possível indagar que é necessário ter uma abordagem adequada à gestante soropositiva, realizar ações para prevenção da TV do HIV e observar que o enfermeiro possui um papel indispensável a oferecer uma assistência a esse público.

Errico et al. (2017) afirma que o PNAR desenvolvido na atenção secundária deve ser assistido por equipe multiprofissional, que inclui o profissional enfermeiro. Dentre as ações do enfermeiro em uma equipe multidisciplinar enfatizase a consulta de enfermagem que, no contexto pré-natal, permite evidenciar as complicações reais da gestante e, por conseguinte, preparar a organização das ações de cuidado indispensáveis e baseando-se em evidências científicas, podem exceder a visão pré-estabelecida na qual o enfermeiro tem desempenho restringido em espaços onde há o domínio das tecnologias dura e leve-dura. 
Discordando da afirmação acima Costa, Silva e Medeiros (2015) relatam que independentemente de estar predito que a atenção à gestante no PNAR deva ser realizada por uma equipe multidisciplinar, a atuação do enfermeiro na atenção secundária não é coerente com o espectro de suas atribuições técnicas, destacando que o enfermeiro pode atuar nos mais diferentes níveis de atenção, porém é na atenção primária que o enfermeiro pode desenvolver ações que minimizem o risco de exposição vertical precocemente. Concordando com essa afirmação a Organização Mundial da Saúde (OMS) afirmou que 80\% das demandas de saúde deveriam ser resolvidas na Atenção Primária.

No entanto, Barrêto e Souza (2019) afirmam que o enfermeiro é o incumbido pelo primeiro contato com as gestantes soropositivas, com atenção no acolhimento, pois a partir deste momento se dá início ao fluxo do atendimento multiprofissional. Após o primeiro contato fazem a admissão da gestante soropositiva já consciente do seu diagnóstico, proporcionam informações sobre o serviço fazendo seguimentos internos para a equipe multiprofissional, conforme as exigências mencionadas na assistência inicial do acolhimento dessa gestante.

\subsection{O papel do enfermeiro como orientador do autocuidado durante o pré-natal de soropositivas}

É indispensável à assistência e a orientação do enfermeiro sobre prevenir riscos e problemas, não necessitando limitar ações clínico-obstétricas, e acrescentar ações de educação em saúde como prática habitual da assistência integral. Assim as habilidades do enfermeiro ao longo do pré-natal de soropositivas sobressaem métodos educativos para a prevenção do HIV diante do binômio mãe/filho. Com relação ao acolhimento na assistência pré-natal, o MS realizou a execução de normas efetivas de saúde pública, como a efetuação de exames para a investigação da infecção pelo HIV.

Quando se trata da atuação do enfermeiro sobre gestantes soropositivas, o principal objetivo segundo o manual de prevenção a IST's é em relação ao pré-natal, afirma Ribeiro et al. (2017). A OMS oferta a prática da educação em saúde como os aconselhamentos, pois é uma ferramenta de grande relevância e importante na prevenção, no diagnóstico e na assistência dos indivíduos que se encontram infectados com HIV, pois colabora para a aceitação de hábitos sexuais mais seguros, a atenuação do impacto da descoberta do diagnóstico, o progresso do autocuidado e a promoção da atenção integral. Através da abordagem sindrômica o enfermeiro tem conhecimento das gestantes soropositivas e outras IST, sendo capaz diagnosticar a infecção pelo vírus no início e promovendo uma assistência adequada e individual.

Confirmando essa opinião Silva \& Silva (2018) evidencia a importância do acompanhamento pré-natal eficaz, pelos enfermeiros da atenção básica, visto que, geralmente, é os primeiros a terem contato com esse público e a ofertar o teste para detecção do vírus. A função do enfermeiro, na unidade de saúde da família, frente às gestantes soropositivas deve ser baseada na interação e na relação de confiança. O papel do enfermeiro sempre é o da orientação, com foco na escuta sobre as preocupações e dúvidas das usuárias respeitando sempre a particularidade de cada uma.

Consequentemente compete aos profissionais de saúde estar qualificados para procurar diminuir espaço correspondente a escassez de acesso às informações por parte das mulheres que vivem com HIV e o déficit de instruções destas quanto a TV do HIV. Confirmando a veracidade do ponto de vista do estudo citado acima Errico et al. (2017) destaca, que o papel do enfermeiro no íntimo do seu suporte formativo, a educação em saúde, tendo potencial de dominar o processo clássico de troca de informação, direcionando a pessoa a pensar muito sobre um assunto e decidir quanto à adoção de hábitos saudáveis. Com o intuito de alcançar tal objetivo, faz-se urgente a aplicação de tecnologias que simplifiquem esse método de ensino.

\subsection{Dificuldades encontradas pelo enfermeiro no cuidado a gestantes soropositivas}

A atuação do enfermeiro na assistência do pré-natal de soropositivas é de suma importância e envolve muitas perspectivas; no entanto, ainda atravessa alguns obstáculos e contrariedades. Para isto, é indispensável a clareza do contexto 
que circunda essa atividade para que as resultâncias da prática do enfermeiro intensifiquem a sua colaboração para diminuir esses riscos à exposição do HIV por meio da transmissão vertical.

Santos et al. (2017) evidencia algumas causas referentes à dificuldade na assistência ao pré-natal, são múltiplos e estão ligados a inúmeras causas, dentre elas, está à relutância em aceitar a gestação. Outro fator, diz respeito à descoberta tardia da gestação para realização do pré-natal. Por conseguinte, nota-se que este causa dificulta à descoberta da soropositividade e aceitação as condutas preconizadas em tempo não hábil. Para além destes fatores, há outros motivos que impossibilitam a realização do pré-natal: acesso aos serviços de saúde, interrupção na realização das consultas e não adesão ao tratamento. Isto se deve ao contexto em que estão inseridas, à subordinação econômica, dependência do parceiro e a relação de gênero existente na sociedade.

Em estudo, observou-se alguns obstáculos para uma adequada atuação do enfermeiro relacionado à assistência no prénatal de soropositivas, ou seja, ligado ao contexto operacional, técnico ou da própria circunstância de vida dessas mulheres. Um desses obstáculos de acordo com Costa, Silva \& Medeiros (2015) foi à procura dessas gestantes com infecção por HIV de menor continuidade às consultas de pré-natal em relação às gestantes sem esse tipo de infecção.

Barrêto e Souza (2019) afirmam que a gestante soropositiva necessita de atendimento de forma integral, iniciando na atenção primária, inclusive com relação ao atendimento de referência e contrarreferência de uma equipe multiprofissional. No entanto, Costa, Silva e Medeiros. (2015) discordam da afirmação acima, pois dizem que umas das principais dificuldades na coordenação do cuidado, muitas vezes, é que não se têm a referência e contrarreferência entre os profissionais dos diversos setores, dificultando assim a assistência desse público.

\section{Conclusão}

Diante do contexto abordado, percebeu-se que a infecção pelo HIV nos últimos anos vem crescendo, e o enfermeiro possui um papel importantíssimo na Atenção Primária de Saúde (APS) pois vem contribuindo bastante para a diminuição da transmissão desse vírus em gestantes soropositivas, evitando assim a TV. Constatou-se que o maior número de gestantes é diagnosticada com HIV durante o pré-natal e que a dedicação do enfermeiro vem a ser primordial dentro desse cenário no que se refere à promoção da saúde em suas diversas direções, sejam elas ações preventivas, educativas ou holísticas.

A pesquisa apontou que gestantes soropositivas requerem de uma assistência em saúde integral e de qualidade. Sendo assim, o enfermeiro deve encontrar-se enquadrado na rede de apoio por intermédio de ações educativas que propiciem a essas mulheres o empoderamento e autossuficiência sobre sua saúde. A promoção da saúde é um conceito importante para que as gestantes soropositivas alcancem uma condição de vida satisfatória e proporciona uma assistência para que continuem protegidas durante o pré-natal.

Dessa maneira, a pesquisa colabora para que o enfermeiro cogite acerca de suas condutas e procure desempenhar a assistência objetivando a promoção da saúde desse público-alvo de maneira diferenciada, individualizada, ética e efetiva. Principalmente livre de julgamentos e preconceitos, portanto a pesquisa traz evidências para a assistência do enfermeiro na atenção ao pré-natal de soropositivas, estas inseridas no pré-natal de alto risco, porém esse público possui um primeiro contato de assistência na atenção primária, cujas ações são organizadas de forma sistemática e baseadas em evidências cientificas, podendo superar a visão pré-estabelecida.

\section{Referências}

Araújo, E. C., Monte, P. C. B., \& Haber, A. N. C. A. (2018). Avaliação do pré-natal quanto à detecção de sífilis e HIV em gestantes atendidas em uma área rural do estado do Pará, Brasil. Revista Pan-Amazônica de Saúde, 9(1), 33-39, http://dx.doi.org/10.5123/s2176-62232018000100005. 
Balsells, M. M. D., Oliveira, T. M. F., Bernardo, E. B. R., Aquino, P. S., Damasceno, A. K. C., Castro, R. C. M. B., Lessa, P. R. A., \& Pinheiro, A. K. B. (2018). Avaliação do processo na assistência pré-natal de gestantes com risco habitual. Acta Paulista de Enfermagem, 31(3), 247-254, https://doi.org/10.1590/1982-0194201800036.

Barrêto, L. G. P., \& Souza, Z. C. N. (2019). Assistência à gestação HIV + na perspectiva multiprofissional em saúde. Anais seminário de iniciação científica, Feira de Santana, 1(22), 1 4, http://dx.doi.org/10.13102/semic.v0i22.4150.

Beck, S., Cauzzo, L., Vielmo, L., \& Andrade, C. (2018). Perfil de gestantes em tratamento para infecção pelo vírus da imunodeficiência humana. Jornal de Epidemiologia e Controle de Infecção, 8 (3), 210-215, https://doi.org/10.17058/reci.v8i3.11190.

Brasil. (2017). Ministério da Saúde. Guia de Vigilância em Saúde: volume 2 / Ministério da Saúde, Secretaria de Vigilância em Saúde, Coordenação-Geral de Desenvolvimento da Epidemiologia em Serviços.

Carvalho, A. K. C., \& Campos, E. A. D. (2018). Assistência a gestante portadora do vírus da imunodeficiência humana. Revista Brasileira de Enfermagem, 71(1), 631-636. Recuperado em 04 de março, 2019, http://www.scielo.br/scielo.php?script=sci_arttext\&pid=S0034-71672018000700631\&lng=en\&nrm=is.

Caus, E. C. M., Santos, E. K. A., Nassif, A. A., \& Monticelli, M. (2012). O processo de parir assistido pela enfermeira obstétrica no contexto hospitalar: significados para as parturientes. Escola Anna Nery, 16(1), 34-40, https://doi.org/10.1590/S1414-81452012000100005.

Coelho, E. O. E. (2018). O Conceito de Conforto na Estratégia Saúde da Família, 94 f. Mestrado (Pós-graduação) - Curso de Enfermagem, Universidade Federal do Estado do Rio de Janeiro-UFERJ, Rio de Janeiro. http://www.repositoriobc.unirio.br:8080/xmlui/bitstream/handle/unirio/11726/O\%20conceito\%20de\%20conforto\%20na\%20estrat\%C3\%A9gia\%20sa \%C3\%BAde\%20da\%20fam\%C $3 \%$ ADlia.pdf?sequence=1.

COFEN. Resolução COFEN $\mathrm{N}^{\circ}$ 516/2016 - Alterada pela Resolução COFEN No 524/2016. http://www.cofen.gov.br/resolucao-cofen-no05162016_41989.html.

Costa, R., da Silva, R., \& de Medeiros, S. (2015). Nursing care across the prevention of vertical transmission of HIV. Revista de Pesquisa: Cuidado é Fundamental Online, 7(1), 2147-2158, http://dx.doi.org/10.9789/2175-5361.rpcfo.v7.3529.

Cunha, M. A., Mamede, M. V., Dotto, L. M. G., \& Mamede, F. V. (2009). Assistência pré-natal: competências essenciais desempenhadas por enfermeiros. Escola Anna Nery, 13(1), 145-153, https://doi.org/10.1590/S1414-81452009000100020.

Errico, L. S. P., Bicalho, P. G., Oliveira, T. C. F. L., \& Martins, E. F. (2018). O trabalho dos enfermeiros no pré-natal de alto risco na perspectiva das necessidades humanas básicas. Revista Brasileira de Enfermagem, 71 (Suppl. 3), 1257-1264, https://doi.org/10.1590/0034-7167-2017-0328.

Goulart, C. S., Mariano, V. T., Castilho, W. R. F., Segura, J. S. N., \& Mota, W. H. (2018). Percepção do enfermeiro da atenção básica da gestante soropositivo. Jornal de saúde e ciências biológicas, 6(3), 286-29, http://dx.doi.org/10.12662/2317-3076jhbs.v6i3.1976.p286-292.2018.

Lima, A. C. M. A. C. C., Bezerra, K. C., Sousa, D. M. N., Vasconcelos, C. T. M., Coutinho, J.F.V., \& Oriá, M.O.B. (2018). Educational technologies and practices for prevention of vertical HIV transmission. Revista Brasileira de Enfermagem, 71(Suppl. 4), 1759-1767, https://doi.org/10.1590/0034-7167-20160333.

Lima, S. S., Silva, L. C. S., Santos, M. V., Martins, J. P., Oliveira, M. C., \& Brasileiro, M. E. (2017). HIV na gestação: pré-natal, parto e puerpério. Ciência e Saúde, Campinas, 10(1), 56-61, http://dx.doi.org/10.15448/1983-652X.2017.1.22695.

Matumoto, S., Fortuna, C. M., Kawata, L. S. K., Mishima, S. M., \& Pereira, M. J. B. (2011). A prática clínica do enfermeiro na atenção básica: um processo em Construção. Rev. Latino-Am. Enfermagem. São Paulo, 19(1), 1-8. http://www.redalyc.org/pdf/2814/281421953017.pdf.

Ribeiro, A. C. O., Neto, R. V. B., Leite, A. B., \& Prado. (2017). Assistência de enfermagem à mãe e bebê portadores de HIV / AIDS. Congresso Internacional de Enfermagem - CIE, Aracaju - SE, 1(1), 1-5. https://eventos.set.edu.br/index.php/cie/article/view/6041/2336.

Santos, S. M., Santos, D. S. S., Bispo, T. C. F., Nunes, F. N., Silva, L. G. P., \& Lima, R. S. C. P. (2017). Transmissão vertical do HIV: Dificuldade na adesão ao pré-natal. Revista Médica Contemporânea - REA, Salvador-BH. 6(1), 56-61, http://dx.doi.org/10.17267/2317-3378rec.v6i1.1109.

Silva, J. M., \& Silva, F. A. (2018). Enfermagem e a prevenção da transmissão vertical do HIV: uma revisão integrativa. Revista interdisciplinar centro universitário uninovafapi, Teresina, 11(1), 95-104. https://revistainterdisciplinar.uninovafapi.edu.br/index.php/revinter/article/view/1258.

Silva, J. M., \& Silva, S. F. (2018) A enfermagem e a prevenção da transmissão vertical do HIV: uma revisão integrativa. Revista Interdisciplinar, Teresina, 11(1), 95-104, http://dx.doi.org/10.17648\%2F2317-5079.v11n1.1258.

Silva, R. C. A., \& Santana, U. M. (2013). Cuidados de enfermagem na transmissão vertical do HIV em parturientes por meio da amamentação. 2013. 22 f. Monografia (Especialização) - Curso de Enfermagem, Faculdade Integrada de Pernambuco-FACIPE, Recife, 2013. http://openrit.grupotiradentes.com/xmlui/bitstream/handle/set/2058/CUIDADOS\%20DE\%20ENFERMAGEM\%20NA\%20TRANSMISS\%C3\%83O\%20VER TICAL\%20DO \%20HIV\%20EM\%20PARTURIENTES\%20POR\%20MEIO\%20DA\%20AMAMENTA\%C3\%87\%C3\%83O.pdf?sequence=1. 